\title{
A REVIEW OF BURDEN OF CAREGIVERS OF PATIENTS WITH ALZHEIMER'S DISEASE
}

Sayyidah Aqilah Ridzuan ${ }^{1}$, Siti Eliza Darussalam ${ }^{1}$, Nur Hazrina Mohamed Hisham ${ }^{1}$, Prashaantini Namasivayam ${ }^{1}$, Yam Min Yi Nichole ${ }^{1}$, Danial Syafiq Shahrir Zaid ${ }^{1}$, Nurul Huda Mohd Nor ${ }^{1}$, Mohd Hazmi Mohamed ${ }^{1}$, Ching Siew Mooi ${ }^{1}$, Navin Kumar Devaraj ${ }^{1}$, Iskasymar Bin Itam Ismail ${ }^{1}$, Hasnur Zaman Hashim ${ }^{1}$, Liyana Najwa Inche Mat ${ }^{1,2}$, Hoo Fan Kee ${ }^{1}$, Hamidon Basri $^{1}$, Wan Aliaa Wan Sulaiman ${ }^{1,2}$

Correspondence: wanaliaa@upm.edu.my

${ }^{1}$ Faculty of Medicine and Health Sciences Universiti Putra Malaysia, Serdang 43400, Malaysia. ${ }^{2}$ Malaysian Research Institute of Ageing (MyAgeing) Universiti Putra Malaysia, Serdang 43400, Malaysia.

\section{Article History:}

Received: January 27, 2018

Accepted: November 27, 2018

Published: January 1, 2019

\section{Cite this as:}

Ridzuan SA, Darussalam SE, Hisham NHM, Namasivayam P, Nichole YMY, Zaid DSS, et al. Factors and interventions of the burden among the caregivers of patients with alzheimer's disease. Malang Neurology Journal; 2019.5:42-45. DOI:

http://dx.doi.org/10.21776/ub.mnj 2019.005.01.7

\section{ABSTRACT}

Many are still unaware of the fact that Alzheimer's disease (AD) also affects the caregivers quite significantly. Caregivers refer to people who are accountable of taking care of AD patients which provide helps with his or her daily living activities and may become a full-time commitment for the caregiver. This gives rise to a concept called caregiver burden. As these caregivers spend most of their time taking care of $\mathrm{AD}$ patients, most of them suffer psychologically as well as physically. Unfortunately, the risk of mental and physical impairment among the caregivers of Alzheimer's patient may cause poor quality of life to both the patients and their caregivers. In addition, due to their role and responsibilities as a caretaker, they often do not have the opportunity to seek help and advices. This review article was conducted by sieving through numerous literature and studies regarding the challenges and how to help the burden of the caregivers of Alzheimer's patients . This paper aims to give and overview, suggestions as well as to increase the awareness of the caregiver's burden.

Keywords: Dementia, Alzheimer's disease, caregivers, factors, interventions, care, burden

\section{Introduction}

Alzheimer's disease is the commonest type of dementia caused by the beta amyloid protein. ${ }^{1}$ The memory loss is chronic and often it is always confused with delirium which is more acute. ${ }^{2}$ Many are still unaware of the fact that Alzheimer's disease (AD) also affects the caregivers quite significantly. Caregivers refer to people who are accountable of taking care of $\mathrm{AD}$ patients which provide helps with his or her daily living activities and may become a full-time commitment for the caregiver. This gives rise to a concept called caregiver burden. As these caregivers spend most of their time taking care of AD patients, most of them suffer psychologically as well as physically. Several studies had showed many deleterious effects on the caregivers. A Stress Process Model proposed by Leonard Pearlin identifies key variables and their relationships namely primary and secondary stressors. ${ }^{3}$ The primary stressors on the caregiver are derived from either objectively from the burden the symptoms of $\mathrm{AD}$ itself such as memory loss, functional loss, and behavior problem or subjectively from the extent to which the caregiver feels the burdens. The secondary stressors arise from the caregivers' other responsibilities and commitments such as family and work as well as ways of managing the stress as well as coping strategies. ${ }^{4}$ Unfortunately, the risk of mental and physical impairment among the caregivers of Alzheimer's patient may cause poor quality of life to both the patients and their caregivers. In addition, due to their role and responsibilities as a caretaker, they often do not have the opportunity to seek help and advices. This review article was conducted by sieving through numerous literature and studies regarding the challenges and how to help the burden of the caregivers of Alzheimer's patients. This paper aims to give and overview, suggestions as well as to increase the awareness of the caregiver's burden.

\section{Factors of burden among caregivers of Alzheimer's patients}

\section{Stress, anxiety and depression}

The prevalence of the mental health disorders such as stress, anxiety and depression as well as physical illness among the caregivers are more common than we thought as depicted in Table 1. According to a study conducted among Italian caregivers, $56 \%$ of them suffered from physical illness and $32 \%$ suffered from psychological illness. ${ }^{5}$ Meanwhile, another study conducted by Ferrara et al. also prove that caregiver burden is heavy, as $53 \%$ out of 200 of them claim that most of their time are spent taking care of the AD patients, and very little are spent for themselves, and they feel that their own social life is affected. It was also reported that $59 \%$ of them feel emotionally drained. ${ }^{6}$ Interestingly, a research done by Argüelles, Loewenstein, Eisdorfer, \& Argüelles revealed that actually many AD 
caregivers misjudged these $\mathrm{AD}$ patients, assuming that they still have some sort of functionality. Unfortunately, this wrong perception had led to a more depressive state for the caregiver when the patients' status did not fulfil their expectation especially in bowels, bladders and toilet use issues. Support system is also very important factor. If the caregivers do not receive enough support from others, they are at high risk of going into depression due to the heavy burden and responsibilities that they have to bear alone. ${ }^{7}$

As a result of the psychological triggers, caregivers also tend to suffer from longer term physiological changes that cause the cardiovascular system to persistently respond to acute stressors for an interval of six to twelve months. This may result to the rising incidence of chronic illness such as hypertension, and increased risk of poor wound healing. ${ }^{8}$ This is also proven by another study conducted by Wright whereby $\mathrm{AD}$ caregivers were in poorer health condition and had a higher level of depression when compared to non-AD caregivers. ${ }^{9}$ As a consequence, caregivers with emotional and physical strain have a $63 \%$ greater mortality rate as compared to those without strain or non-caregivers. ${ }^{10}$

Table 1. Percentage of caregivers having caregiver burdens in various studies.

\begin{tabular}{|c|c|}
\hline Caregiver burdens & Percentage of people involved \\
\hline Physical illness $^{2}$ & $56 \%$ \\
\hline Psychological illness $^{2}$ & $32 \%$ \\
\hline $\begin{array}{l}\text { Time spent too little on } \\
\text { self and too much on } \\
\text { patient }{ }^{3}\end{array}$ & $53 \%$ \\
\hline Emotionally drained $^{4}$ & $59 \%$ \\
\hline
\end{tabular}

\section{Lack of support services}

The support services are the one of the main important factor to help with the caregivers burden but sadly it is still lacking in most developing countries. With the rising incidence of $\mathrm{AD}$, ageing society should be more aware of the need to give a lifelong support for both AD patients and caregivers. Among the example of support services that need to be increased are nursing service, day center, cleaning service, personal care service and home care services. The importance of the support services is demonstrated in a study in Hong Kong that revealed home care services have improved the functional condition of the elderly. The home care services provided were counseling, training, interest-raising, empowerment, and nursing talks to aid with their transient reduction in functional ability among the elderly in Hong Kong. ${ }^{11}$

However, the support service may not be used fully by caregivers who are unwilling to leave their care receiver with strangers. In addition, some caregivers are unaware of the services and some feel that their care receivers might give a lot of problems to these services because of the AD patients' behavioral and emotional problems. ${ }^{12}$ In addition, Vellone et. al. revealed that in Italy, the high expenses that caregiver has to pay for these kind of services lead to the stress and burden on caregivers. ${ }^{5}$ Therefore, government has to take the lead to provide public support service for a better care of the society.

\section{Poor sleep}

With the burden of taking care of $\mathrm{AD}$ patients for long hours, many caregivers lack rest and subsequently sleep quantity. Moreover, their sleep quality is usually interrupted by their care-receiver at night. Unfortunately, the sleep problem among caregivers persisted even after the care recipient passed away or moved out of the house as shown by a study done by McCurry and his colleague. The study also showed that the less social support the caregiver received, the poorer the sleep quality. A poor quality of sleep will lead to a lower quality of life among the caregivers, and further exacerbate the psychological problem they suffer from the caregiver burden. ${ }^{13}$

\section{Interventions on burden of caregivers of Alzheimer's patients}

Despite the increasing prevalence of Alzheimer's disease, the studies on the caregivers of person with Alzheimer's are still lacking. We have found a holistic approach on the possible interventions to lift up the burden of the caregivers. Table 2 illustrated the summary of the interventions that will be described further.

Table 2. Interventions on burden of caregivers of Alzheimer's patients.

\begin{tabular}{ll}
\hline Interventions & Description \\
\hline Occupational therapy & $\begin{array}{l}\text { Coping behavior and } \\
\text { supervision methods }\end{array}$ \\
\hline Spiritual Therapy & $\begin{array}{l}\text { Strengthen the intrinsic belief } \\
\text { system among the caregivers }\end{array}$ \\
\hline Behavioural interventions & $\begin{array}{l}\text { Interactive sessions of problem } \\
\text { solving and critical thinking } \\
\text { techniques }\end{array}$ \\
\hline Effective coping strategies & $\begin{array}{l}\text { Problem solving skills, decision } \\
\text { making techniques and } \\
\text { techniques to deal with attitude } \\
\text { problems of the Alzheimer's } \\
\text { patients }\end{array}$ \\
\hline
\end{tabular}

\section{Occupational therapy}

Occupational therapy is a customized therapeutic intervention to improve the AD patient's ability to perform daily activities with their limited cognitive ability. A study done by Graff had focused on the outcome of occupational therapy to both dementia patients and their caregivers. The study aimed on intervening with caregivers' behavior by including coping behavior and supervision methods in his occupational therapy, while for the patients, therapy was aimed at cognitive and behavioral interventions. The occupational therapy was shown to have a success in reducing caregiver burden and enhancing patient's quality of life. ${ }^{14}$

\section{Spiritual therapy}

The challenging task of caring for patients with Alzheimer's disease may be reduced with the use of spiritual therapy that strengthens the intrinsic belief system among the caregivers. A study done Beuscher \& Grando revealed that spirituality can help in coping with early stage Alzheimer's disease. These respondents were brought up to use prayers ever since childhood, and prayers was found to be comforting and have granted them hope. ${ }^{15}$ Various studies have shown that spirituality works as a very effective resource for them to cope with the disease too. According 
to Kirkland \& Mcilveen, therapeutic advantages of spirituality in patient and their caregiver includes to make sense of a situation and to have approval and acceptance. Besides the benefit from spiritual therapy, it is practical, easy and economical. ${ }^{16}$

\section{Behavioural interventions}

Another approach to reduce the caregiver burden is through behavioural interventions. Based on a study done, behaviour interventions could improve the negative behavioural symptoms as well as reducing psychologicalrelated problems such as anxiety and depression. ${ }^{4}$

With the advances of technology, behavioural interventions can also be performed virtually. This was proven by a research regarding the trial of 'Mastery over dementia' which was awarded with the Alzheimer Disease International (ADI) award for the 'most promising psychosocial intervention for people with dementia or their caregivers' 2010. 'Mastery over dementia' comprises of 8 sessions of internet interventions with a professional counselor which includes interactive sessions of problem solving and critical thinking techniques. ${ }^{17}$

Intriguingly, telephone intervention is another approach of tackling with behaviour problems among caregiver. In 2013, the efficacy of virtual behavioural intervention were also shown by a research by Tremont et al. with the development of a telephone intervention named 'Family Intervention: Telephone Tracking- Caregiver (FITT-C)'. ${ }^{18}$ It was performed by well-trained therapists via telephone regarding knowledge about dementia, emotional support and coping strategies. However, in another study, a telesupport between 5 caregivers per group for an hour per week only have minimal benefits. ${ }^{19}$ This could be due to lacked of a well-trained therapists or counselor to guide them, has been demonstrated in the previous research. However, this approach is very cost effective and more studies should be done to explore its benefits.

\section{Effective coping strategies}

Coping strategies may vary between caregivers. Engagement and disengagement strategies are two broad categories of coping strategies. ${ }^{20}$ However, disengagement strategies which disengaged the caregivers from the person or the surrounding transaction have clinically significant mental health effects such as anxiety and depression. ${ }^{21}$ This was also supported by a study conducted by Raggi, Tasca, Panerai, Neri, \& Ferri whereby the severity of caregiver burden has association with their disengagement strategies such as having avoidance behavior and problem-focused approach, rather than problem solving. These studies aimed at proposing modified coping strategies in order to reduce caregiver distress and burden. ${ }^{22} \mathrm{~A}$ psycho-educational intervention by the work of Beinart and his research team had aimed at educating the caregiver with effective coping strategies in terms of problem solving skills, decision making techniques and techniques to deal with attitude problems of the Alzheimer's patients. ${ }^{23}$

\section{Conclusion}

In conclusion, handling Alzheimer's patients who has impaired memory, thinking and behaviour is far harder than said or seen. Caring for these patients' falls on the shoulders of family or relatives as one has to continuously need to attend the needs of the patients. It does not only impose a great burden on the patient but it also involves the caregiver as well. This indirectly causes a lot of mental, social and health effects on the caregivers. A combination of interventions for these caregivers to ease their burden would be greatly needed to give a better quality of life for both patients and their caregivers. These, includes psychosocial and occupational therapy that would prepare caregivers to not be emotionally or physically drained. In future, we recommend more studies to be considered by researchers such as on factors of dementia patient's caregivers that contributes to burden or caregiver's burden and their effectiveness in caring dementia patients. Government has to take the lead to provide public support service for a better care of the society.

\section{Acknowledgement}

This work was supported by the UPM Research Fund [grant numbers GPB/2017/9585500].

\section{References}

1. Indra MR, Marhaendraputro EA, Hidayat RR. Beta amyloid polyclonal antibody immunogenicity as early development study of early diagnosis for alzheimer's disease. Malang Neurology Journal; 2017.3:1-4. DOI: http://dx.doi.org/10.21776/ub.mnj.2017.003.01.1

2. Mat LNI, Sulaiman WAW, Kee HF, Baharin MAS, Ghenesan S, Ishak SN, et al. Clinical manifestations of delirium in elderly. Malang Neurology Journal; 2018.4(2):78-85.

DOI: http://dx.doi.org/10.21776/ub.mnj.2018.004.02.6

3. Pearlin LI, Mullan JT, Semple SJ, Skaff MM. Caregiving and the stress process: an overview of concepts and their measures. Gerontologist; 1990 . 30(5):583-94.

https://doi.org/10.1093/geront/30.5.583

4. Brodaty H. Working together: combining pharmacological and psychosocial interventions for people with dementia and caregivers. Alzheimer's Dement; 2010.6(4):S90. Available from: http://linkinghub.elsevier.com/retrieve/pii/S15525260 10003948

5. Vellone E, Sansoni J, Cohen MZ. The experience of italians caring for family members with alzheimer's disease. J Nurs Scholarsh; 2002. 34(4):323-9. DOI: http://doi.wiley.com/10.1111/j.15475069.2002.00323.x

6. Ferrara M, Langiano E, Di Brango T, De Vito E, Di Cioccio L, Bauco C. Prevalence of stress, anxiety and depression in with alzheimer caregivers. Health Qual Life Outcomes; 2008. 6(1):93. DOI: 10.1186/14777525-6-93

7. Argüelles S, Loewenstein DA, Eisdorfer C, Argüelles T. Caregivers' judgments of the functional abilities of the alzheimer's disease patient: impact of caregivers' depression and perceived burden. J Geriatr Psychiatry Neurol; 2001. 14(2):91-8. DOI: https://doi.org/10.1177/089198870101400209

8. Grant I, Adler KA, Patterson TL, Dimsdale JE, Ziegler MG, Irwin MR. Health consequences of 
alzheimer's caregiving transitions: effects of placement and bereavement. Psychosom Med; 2002. 4(3):477-86.

PubMed:

http://www.ncbi.nlm.nih.gov/pubmed/12021421

9. Wright LK. Ad spousal caregivers. Longitudinal changes in health, depression, and coping. J Gerontol Nurs; $1994 . \quad 0(10): 33-48 . \quad$ PubMed: http://www.ncbi.nlm.nih.gov/pubmed/7963293

10. Lutgendorf SK, Laudenslager ML. Care of the Caregiver: stress and dysregulation of inflammatory control in cancer caregivers. J Clin Oncol; 2009. 27(18):2894-5. DOI: 10.1200/JCO.2009.22.1523

11. Cheung $\mathrm{C}-\mathrm{K}$, Ngan RM. Improving older adults' functional ability through service use in a home care program in hong kong. Res Soc Work Pract; 2005. 15(3):154-64.

DOI: https://doi.org/10.1177/1049731504270385

12. Strain LA, Blandford AA. Community-based services for the taking but few takers: reasons for nonuse. J Appl Gerontol; 2002. 21(2):220-35. DOI: https://doi.org/10.1177/07364802021002006

13. McCurry SM, Gibbons LE, Logsdon RG, Vitiello M $\mathrm{V}$, Teri L. Insomnia in caregivers of persons with dementia: who is at risk and what can be done about it? Sleep Med Clin; 2009. 4(4):519-26. PubMed: http://www.ncbi.nlm.nih.gov/pubmed/20046806

14. Graff MJL. Rcts involving occupational therapy with community-dwelling families of individuals with dementia. Alzheimer's Dement; 2010. 6(4):S90. DOI: https://doi.org/10.1016/j.jalz.2010.05.275

15. Beuscher L, Grando VT. Using spirituality to cope with early-stage alzheimer's disease. West J Nurs Res; $2009 . \quad 31(5): 583-98 . \quad$ DOI: $10.1177 / 0193945909332776$

16. Kirkland K, Mcilveen H. Full circle: spiritual therapy for people with dementia. Am J Alzheimer's Dis; 1999. 14(4):245-7
17. Blom MM, Zarit SH, Bosmans JE, Cuijpers P, Pot AM. Effectiveness of an internet intervention for family caregivers of people with dementia: results of a randomized controlled trial. PLoS One; 2015. 10(2):e0116622. DOI: 10.1371/journal.pone.0116622

18. Tremont G, Davis J, Papandonatos GD, Grover C, Ott $\mathrm{BR}$, Fortinsky RH, et al. A telephone intervention for dementia caregivers: background, design, and baseline characteristics. Contemp Clin Trials; 2013. 36(2):33847. DOI: 10.1016/j.cct.2013.07.011

19. Winter L, Gitlin LN. Evaluation of a telephone-based support group intervention for female caregivers of community-dwelling individuals with dementia. Am J Alzheimer's Dis Other Dementiasr; 2007. 21(6):3917. DOI: $10.1177 / 1533317506291371$

20. Jones F, Bright J. Stress: myth,research and theory. Pearson; 2001. Available from: https://www.pearson.com/us/highereducation/program/Jones-Stress-Myth-Research-andTheory/PGM30127.html

21. García-Alberca JM, Cruz B, Lara JP, Garrido V, Gris E, Lara A, et al. Disengagement coping partially mediates the relationship between caregiver burden and anxiety and depression in caregivers of people with alzheimer's disease. results from the málaga-ad study. J Affect Disord; 2012. 136(3):848-56. DOI: 10.1016/j.jad.2011.09.026

22. Raggi A, Tasca D, Panerai S, Neri W, Ferri R. The burden of distress and related coping processes in family caregivers of patients with alzheimer's disease living in the community. J Neurol Sci; 2015. 358(12):77-81. DOI: 10.1016/j.jns.2015.08.024

23. Beinart N, Weinman J, Wade D, Brady R. Caregiver burden and psychoeducational interventions in alzheimer's disease: a review. Dement Geriatr Cogn Dis Extra; 2012. 2(1):638-48. DOI: $10.1159 / 000345777$ 